\title{
The early evolutionary history of neo-sex chromosomes in Neotropical grasshoppers, Boliviacris noroestensis (Orthoptera: Acrididae: Melanoplinae)
}

\author{
Elio R.D. CASTILLO ${ }^{1,2,3}$, Alberto TAFFAREL ${ }^{1,2,3}$ and Dardo A. MARTÍ1,2 \\ ${ }^{1}$ Laboratorio de Genética Evolutiva, Instituto de Biología Subtropical-Universidad Nacional de Misiones (IBS), \\ Félix de Azara 1552, Piso 6 , CP3300, Posadas, Misiones, Argentina; e-mails: castillo.eliorodrigo@gmail.com; \\ radova@gmail.com; darmarti@yahoo.com.ar \\ ${ }^{2}$ Consejo Nacional de Investigaciones Científicas y Técnicas (CONICET); Av. Rivadavia 1917 (C1033AAJ) \\ Ciudad Autónoma de Buenos Aires, Argentina \\ ${ }^{3}$ Comité Ejecutivo de Desarrollo e Innovación Tecnológica (CEDIT); Felix de Azara 1890, Piso 5º Posadas, \\ Misiones 3300, Argentina
}

Key words. Orthoptera, Acrididae, Melanoplinae, chromosome rearrangement, Dichroplini, genetic divergence, homology, neo-sex chromosomes

\begin{abstract}
Neo-sex chromosomes are an important component of chromosome variation in Orthoptera, particularly South American Melanoplinae species, which have proven to be outstanding experimental model system to study the mechanism of sex chromosome evolution in this group of insects. In terms of their origin, most derived sex chromosome mechanisms involve a Robertsonian fusion (i.e. translocation) between the ancestral X chromosome and an autosome. In the grasshopper, Boliviacris noroestensis Ronderos \& Cigliano (1990) (Orthoptera: Acrididae: Melanoplinae), our results point to a small degree of differentiation (conserved homology between the XR arm and the neo-Y) of the neo-XY chromosomes, which may be of recent evolutionary origin. However, a simple centric fusion model does not explain their origin, mainly because of the observed reduction in the fundamental number (FN) of arms. We propose two models which, we hope, clarify the genesis of $B$. noroestensis neo-sex chromosomes. Records of karyotype variation in related species due to multiple rearrangements support our models. We propose a possible adaptive advantage for neo-sex chromosome carriers, such changes perhaps representing the primary force that increases their frequency within natural populations compared with non-fused translocated forms, and occurring without apparent detriment to the microevolutionary forces that may also act, at least at the beginning of the evolutionary history of individuals bearing such neo-sex chromosomes.
\end{abstract}

\section{INTRODUCTION}

Neo-sex chromosomes are an important component of chromosome variation in Orthoptera (grasshoppers and crickets) and especially in the superfamily Acridoidea. South American melanopline grasshoppers have proven to be an ideal model system for studies of karyotypic evolution in this globally-widespread and often economically-important group of insects; thus most cytogenetic studies have been performed, and most cases of derived sex chromosome changes described, using this system (Hewitt, 1979; Mesa et al., 1982; Castillo et al., 2010a, b). During the origin of neo-sex chromosomes, Robertsonian $(\mathrm{Rb})$ fusions are always involved, a condition which can be exploited to infer stages in the $\mathrm{Y}$ chromosome degeneration process (Charlesworth, 2002; Charlesworth et al., 2005; Bachtrog, 2013). South American melanoplines are of interest in this respect due to a high frequency of neo-sex chromosomes when compared with species of the same subfamily from the rest of the world (Castillo et al., 2010b). Moreover, this subfamily also includes a large number of species which display extreme reductions in chromosome number, mainly due to the occurrence of centric fusions; however, other rearrangements have also played a significant role in karyotype re-structuring (Mesa et al., 1982; Bidau, 1990;
Bidau \& Martí, 1995; Martí \& Bidau, 1995; Colombo et al., 2005; Castillo et al., 2010b).

Robertsonian X-A fusions have occurred several times in the evolutionary history of the Melanoplinae (Mesa et al., 1982, 2001; Bidau \& Martí, 2001; Colombo et al., 2005; Castillo et al., 2010b). Indeed, not only do they show a high frequency of derived systems, but also the observed neo-XY chromosome systems fall within a continuum of evolutionary scenarios showing at one end, a small degree of differentiation where the XR (fused autosome) arm of the neo-X still conserves high homology with the neo-Y; on the other end there is an almost complete loss of homology between the neo-Y and XR. This is evidenced by an extremely reduced synaptic zone and eventually XR heterochromatinization (White, 1973; Hewitt, 1979; Castillo et al., 2010a). Recent work on melanopline species using $C_{0} t-1$ DNA fraction mapping point to a relatively restricted spreading of this repetitive DNA in neo-sex chromosomes, which contrasts with the repetitive DNA accumulation expected after recombination restriction (Palacios-Gimenez et al., 2013). Research also suggests different accumulation/diversification patterns of repetitive DNAs of neo-Y chromosomes in related species (Palacios-Gimenez et al. 2013); such empirical data is evidence for the loss of selection pressure in chromosomal regions where recombina- 
tion is abolished, leading to a high rate of genetic diversification (Palacios-Gimenez et al., 2013). Between these two extreme cases, a continuum of neo-sex chromosome evolutionary stages and those pertaining when the process is apparently complete are found (Mesa, 1962a, b; Sáez, 1963; Díaz \& Sáez, 1968; Sáez \& Pérez-Mosquera, 1977; Cardoso \& Dutra, 1979; Mesa et al., 1982; Martí \& Bidau, 2001; Carbonell \& Mesa, 2006). In general terms, there are few records of recently established neo-sex chromosomes, probably due to the fact that the new fixed system has, in the initial stage at least, an accelerate process of differentiation. According to Castillo et al. (2010b), a phylogenetically-distant group (Ommexechidae) includes two cases, namely South American Tetrixocephalus willemsei Gurney \& Liebermann and Neuquenina fictor (Rehn) (both Orthoptera: Acridoidea: Ommexechidae), where chiasmata analyses evidenced more than four crossing-over events between the XR and the neo-Y (Mesa, 1961). In the case of Melanoplinae, spontaneous neo-XY mutants are also expected to behave this way, as it was observed in Leiotettix sanguineus Bruner (Orthoptera: Acridoidea: Acrididae) (Mesa \& Mesa, 1967; Castillo et al., 2010b) but no records of established systems with this characteristics were found.

In the last years cytogenetic information encompassing the origin, structure and meiotic behaviour of melanopline neo-sex chromosomes has increased notably (Mesa et al., 1982; Castillo et al., 2010a, b; Palacios-Gimenez et al., 2013). In general terms, the information provided by recent work has begun to clarify some questions concerning the mechanisms involved in the origin of these sex chromosome changes, but different outcomes could be inferred according to several recent papers (Kaiser \& Bachtrog, 2010; Bidau et al., 2011; Palacios-Gimenez et al., 2013). Besides, researchers also extrapolate theoretical and empirical data from other biological models in order to shed light on how sex could be determined in Orthoptera (White, 1973; Pannell \& Pujol, 2009; Kaiser \& Bachtrog, 2010; Bidau et al., 2011).

Within the framework of derived sex chromosomes in recent and advanced evolutionary stages, the main objective of the present study is to describe the karyotype of $B o$ liviacris noroestensis Ronderos \& Cigliano (1990) and to discuss the origin of its sex chromosome system in the context of Neotropical Melanoplinae neo-sex chromosomes.

\section{MATERIAL AND METHODS}

Male and female adult of $B$. noroestensis grasshoppers were sampled from two localities: Sauzalito, Chaco in Argentina $\left(\mathrm{n}=2 \mathrm{O}^{\mathrm{N}}\right)\left(24.424^{\circ} \mathrm{S}, 61.683^{\circ} \mathrm{W}, 170 \mathrm{~m}\right.$ a.s.1. $)$ and Filadelfia, Bo-

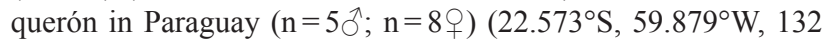
m a.s.1.) from 2008 to 2012. Voucher specimens were deposited in the collection of the Laboratorio de Genética Evolutiva of the Facultad de Ciencias Exactas Químicas y Naturales, IBS, CONICET-UNaM.

Male meiotic preparations were performed by squashing testes follicles in ferric hematoxylin. Mitotic metaphase chromosomes from female gastric caeca were obtained following the procedure described by Castillo et al. (2011).

Silver staining of kinetochores and chromatid cores were performed according to the procedure of Rufas (1985). Briefly, air-

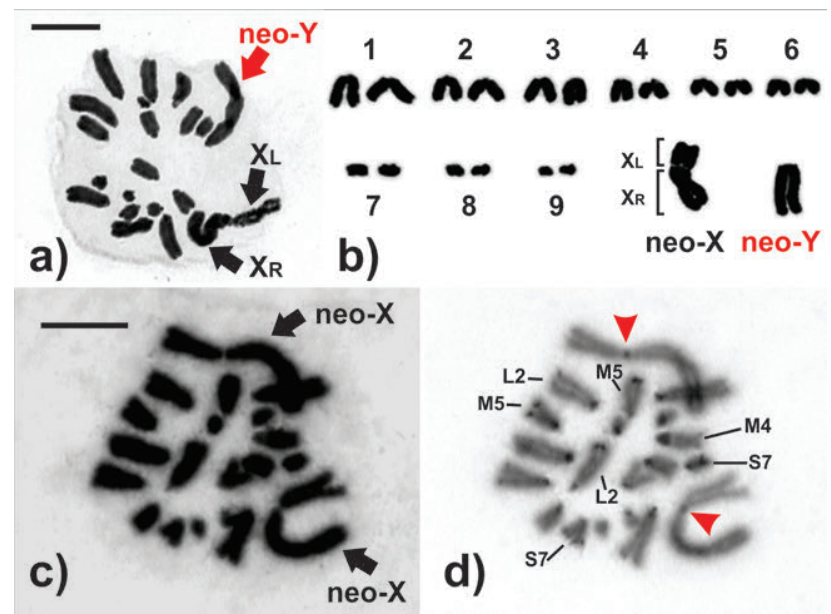

Fig. 1. Spermatogonial metaphase of Boliviacris noroestensis. a - conventional technique; black arrows indicate neo-X arms (negative heteropycnotic XL arm) and the neo-Y (red arrow); $\mathrm{b}$ - karyotype with conventional staining, brackets show neo-X chromosome arms. Mitotic metaphase of female individuals (c) Giemsa staining, arrows indicate neo-XX sex chromosomes; d - C-banding; L2, M5, S7 and M4 pairs are indicated; neo-sex chromosome centromeric heterochromatin is shown with red arrows. $\mathrm{Bar}=10 \mu \mathrm{m}$.

dried male meiotic preparations were incubated in $2 \times \mathrm{SSC}$ at $60^{\circ} \mathrm{C}$ for $10 \mathrm{~min}$ and stained with $50 \% \mathrm{AgNO}_{3}$ in $\mathrm{dH}_{2} \mathrm{O}(\mathrm{pH}$ adjusted to 3.5 with formic acid). Microscopic observation of silver stained preparations involved bright field and Nomarski interference optics. C-banding was performed following the protocol of Sumner (1972), with modifications.

Chiasmata were scored at metaphase I with ten cells from each of seven males, classified following inspection as proximal (P), interstitial (I) and distal (D), corresponding to their presence in the first (para-centromeric), second, or third portion of the chromosome arm, respectively, when divided into three equal regions. We used White's (1973) terminology to refer neo-sex chromosomes arms.

\section{RESULTS}

Boliviacris noroestensis showed a karyotype $2 \mathrm{n}=20 \hat{\mathrm{O}} \mathrm{l}$ $20 \circ, \mathrm{FN}=21 \delta / 22 ᄋ$, with all autosomes telocentric and a neo-XY sex-chromosome mechanism. The male karyotype had nine autosomal pairs grouped in three large (L1-L3), three medium-sized (M4-M6), and three small (S7-S9), plus a heteromorphic sex chromosome pair (Fig. 1a, b). As is usual within some melanopline groups, the species appeared to show an S7 megameric autosomal bivalent (Fig. 2b).

All chromosomes in female mitotic metaphase (Fig. 1c) showed small pericentromeric heterochromatic C-positive blocks (Fig. 1d). Furthermore, we found evidence for variations in the distribution of distal $\mathrm{C}$ positive blocks. However, a constant pattern was observed in L2, M5 and S7 pairs, showing the same size of pericentromeric blocks; M4 was polymorphic for a prominent paracentromeric C positive block (Fig. 1d).

Concerning the morphology and structure of sex chromosomes, they comprise a submetacentric neo-X and a telocentric neo-Y, the latter being distinguished from autosomes in mitosis due to its large size (Fig. 1a). Also, in 

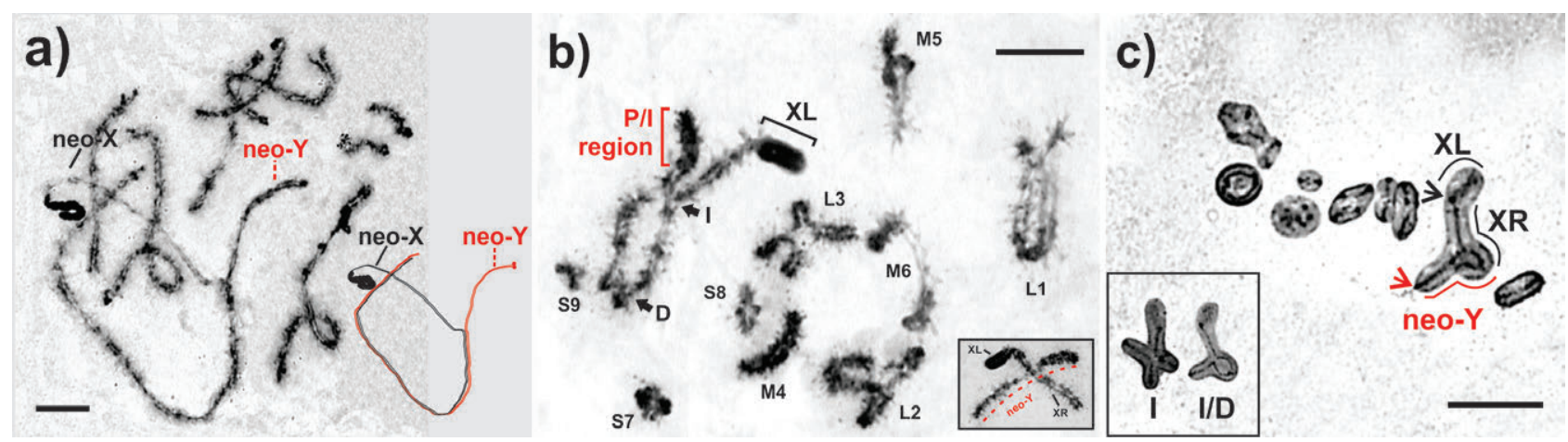

Fig. 2. Conventional staining. a - complete pachytene nucleus of Boliviacris noroestensis male showing neo-X and neo-Y arrangements; at the bottom right the schematic representation of the neo-X (black) and neo-Y (red) synaptic configuration is shown; $b$ - diplotene stage: black brackets indicate the XL arm of the neo-X, red brackets the proximal-interstitial (P/I) region; distal and interstitial chiasmata between the sex pair are indicated with black arrows; at the bottom right of the figure is shown the sex bivalent; in black the arm of the neo-X and the neo-Y with red dotted lines; $\mathrm{c}$ - silver impregnation of scaffolds (kinetochores and chromatid cores) of metaphase I bivalents; at the bottom right the schematic drawing are shown the neo-X arms (black lines) and the neo-Y (red lines); the kinetochores from each are indicated with thin arrows; two different configuration of the neo-sex chromosome bivalent are shown at the bottom left. $\mathrm{Bar}=10 \mu \mathrm{m}$.

metaphase I we observed that the XR arm is twice the size of the XL arm (Fig. 2c).

In all specimens analyzed, the XL arm showed the typical allocyclic behaviour of the acridoid $\mathrm{X}$ chromosome during late pachytene and diplotene (Fig. 2a, b). In addition, using conventional staining we observed a similar condensation pattern in the neo-Y proximal-interstitial region, while the $\mathrm{XR}$ and the interstitial-distal region of the neo-Y still conserved complete homology as well as euchromatic behaviour (Fig. 2b). However, at the diplotene stage, we identified the proximal-interstitial region using C-banding and C-banding combined with DAPI staining (Fig. 3a, b).

In males, pachytene nuclei revealed an incomplete synaptic configuration between the interstitial-distal region of the XR arm and the proximal-interstitial region of the neo-

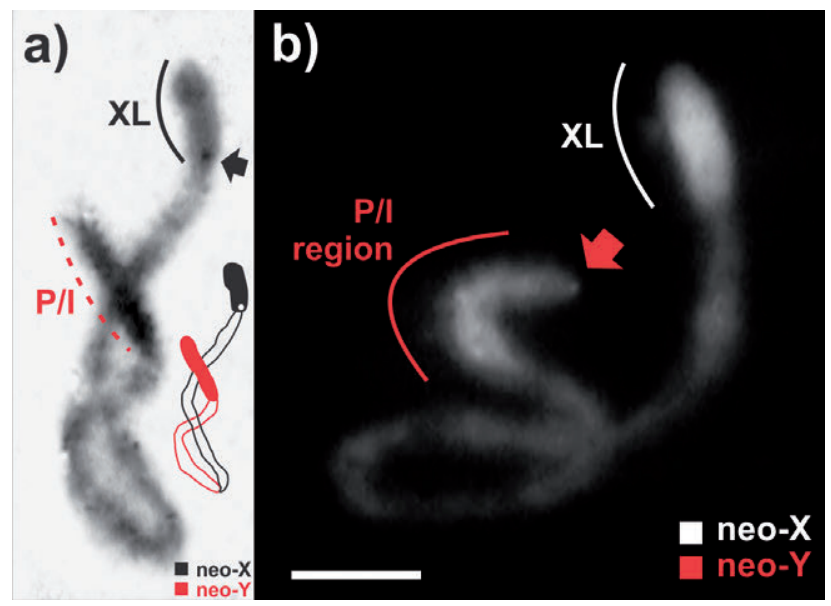

Fig. 3. Neo-sex chromosomes at the diplotene stage. a - Cbanding; black lines show the XL arm, the C-positive pericentromeric heterochromatin of the neo- $\mathrm{X}$ is indicated with arrow and the proximal-interstitial region $(\mathrm{P} / \mathrm{I})$ with dotted red lines; at the bottom right a schematic interpretation of the bivalent is shown; b - C-banded sex chromosome bivalent, stained with DAPI, red line shows the proximal-interstitial region of the neo-Y and their pericentromeric heterochromatin is indicated with a red arrow; white line shows the XL arm. Bar $=5 \mu \mathrm{m}$.
$\mathrm{Y}$ (Fig. 2a). In metaphase I neo-X and neo-Y centromeres were distantly localized from the pairing region, thus two configurations could be observed in this phase. In addition to a high frequency of distal-interstitial chiasmata (78\%) we also observed interstitial chiasmata $(22 \%)$ between neo-X and neo-Y in all the cells analyzed $(n=70)$ (Fig. 2c).

In female mitotic metaphases and male diplotenes, the neo-X centromeric region was identified by $\mathrm{C}$-banding (Figs 1d, 3a). Additionally the proximal-interstitial region of the neo-Y was found to display a large heterochromatic block (Fig. 3a, b).

Upon performing the scaffold technique with silver impregnation, neo-XY chromosome kinetochores and the fibrous network of non-histone proteins (scaffolds) were observed at metaphase I. The XL arm of the neo-X showed the typical interchromatidic axis of the ancestral X chromosome without any particular structure, as with those observed in differentiated neo-sex chromosome systems [e.g. Ronderosia bergi (Stål) (Orthoptera: Acrididae: Melanoplinae)](Castillo et al., 2010a). The XR and the neo-Y showed a typical autosomal scaffold configuration (Fig. 2c).

\section{DISCUSSION}

The occurrence of neo-sex chromosomes has been well documented in Orthoptera and in other insect orders with X0/XX systems, such as Coleoptera (Viturri et al., 2003) and Lepidoptera with ZW/ZZ systems (i.e. with heterogametic females) (White, 1973; Hewitt, 1979; Traut, 1999; Traut et al., 2007; Castillo et al., 2010b). While the Z0/ $\mathrm{ZZ}$ condition is ancestral, present in all basal lineages of Lepidoptera, cases of Z0/ZZ among more "advanced" insect species are sporadic and considered to be due to secondary loss of the $\mathrm{W}$ chromosome (Sahara et al., 2012). As a matter of fact in some cases, X0/XX systems are thought to be the last stages of sex chromosome differentiation. However, they are not as such "dead ends" of sex chromosome evolution. Empirical evidence of chromosome 


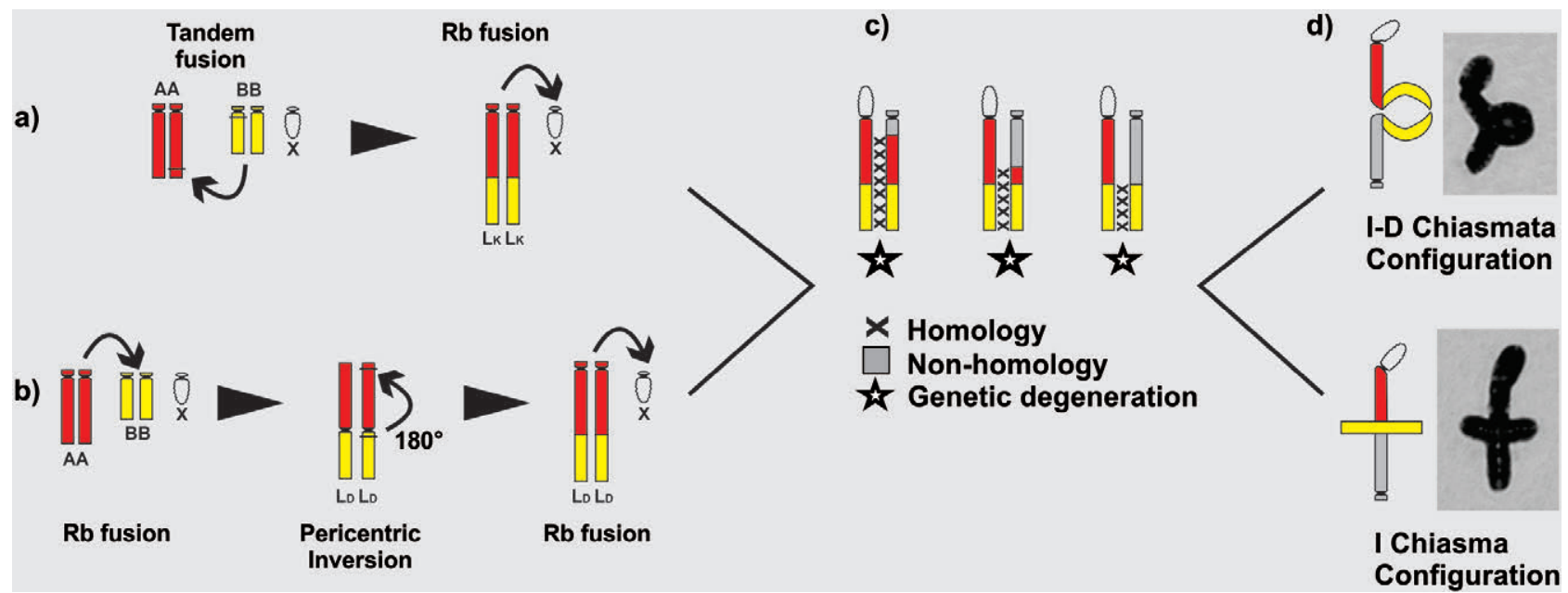

Fig. 4. Schematic view of the origin of neo-sex chromosomes in Boliviacris noroestensis produced by complex chromosome restructuring, explained using two models: a - tandem fusion between two autosome pairs AA (red) and BB (yellow) producing a pair of large autosome $\left(\mathrm{L}_{\mathrm{K}}\right)$; one of the $\mathrm{L}_{\mathrm{K}}$ autosome then is fused with the $\mathrm{X}$ chromosome; $\mathrm{b}$ - first, Robertsonian translocation between two autosome pairs took place; then a pericentric inversion became established producing a large telocentric pair $\left(\mathrm{L}_{\mathrm{D}}\right)$. Later the $\mathrm{L}_{\mathrm{D}}$ autosome fused with an $\mathrm{X}$ chromosome. $\mathrm{c}$ - in the resulting neo-sex chromosome pair, the neo-XR and the neo-Y still conserve significant homology (indicated by "X"); $d$ - two meiotic configurations of neo-XY bivalents showing interstitial-distal (I/D) chiasmata and interstitial (I) chiasma.

rearrangement, like autosome translocations, creates a neo-Y as in Heteroptera (Jacobs, 2004; Bressa et al., 2009) or neo-W as in Lepidoptera (Traut \& Marec, 1997; Traut et al., 2007). From then on, a new cycle of sex chromosome differentiation is found to begin (Traut, 1999; Traut et al., 2007). In Orthoptera, the most accepted hypothesis for the origin of most neo-chromosome systems is a centric fusion between a standard telocentric $\mathrm{X}$ and a telocentric autosome, producing the neo-X chromosome with the homologue (unfused autosome), becoming then the neo-Y (Mesa, 1962a, b; Sáez, 1963; Díaz \& Sáez, 1968; Sáez \& Pérez-Mosquera, 1977; Cardoso \& Dutra, 1979; Mesa et al., 1982; Martí \& Bidau, 2001; Carbonell \& Mesa, 2006; Castillo et al., 2010a,b). Additionally, there are some records where more than one re-structuring event is involved in their origin [e.g. Dichroplus vittatus Bruner (Orthoptera: Acrididae: Melanoplinae) and $R$. bergi] (Bidau \& Martí, 2001; Castillo et al., 2010a).

The neo-sex chromosome system spectrum seen in Neotropical South American grasshoppers is wide and only a few of such events have been described in the initial step of the differentiation process, including here in the case of $B$. noroestensis. In three species examined, a recent replacement of the X0-XX sex chromosome system took place $(N$. fictor, T. willemsei, L. sanguineus) (Mesa, 1961; Mesa et al., 2001). Recently arisen neo-sex chromosomes will be initially represented by a pair of sex chromosomes, which still conserves extensive homology, synaptic ability and the chance of free recombination along the fused autosome (XR) and its homologue, now the neo-Y (Castillo et al., 2010b).

Based on our observations, the single centric fusion model cannot explain neo-sex chromosome origin of $B$. noroestensis. In the first place, the autosome size involved in the fusion is twice the length of a typical L1 pair. Be- sides, if a single $\mathrm{X}-\mathrm{A} \mathrm{Rb}$ fusion was involved, the ancestral $\mathrm{FN}=23 / 24$ should be maintained. Our results revealed not only a reduction in the chromosome number but also in the number (FN) of arms. Furthermore, we observed a submetacentric neo-X chromosome with a large XR arm, similar in size to the neo-Y, at early-diplotene. In metaphase I, the scaffold structure of the neo-XY in all analyzed cells revealed two disjunctional configurations; despite 'cross' -shaped configurations due to interstitial chiasmata which could distort segregation, although anomalous spermatids were not observed among a sample of 700 inspected. The standard X chromosome of grasshoppers is invariably allocyclic during male meiosis and strongly negatively heteropycnotic at metaphase I. This behaviour is conserved even when the $\mathrm{X}$ is fused to an autosome. Thus, the XL arm has a typical positive heteropycnosis but the XR maintains an euchromatic state (White, 1973; Hewitt, 1979; John, 1983). Additionally, a different condensation pattern was observed in the neo-Y: in the diplotene stage, its proximalinterstitial region shows a particularly condensed pattern while the interstitial-distal region is euchromatic.

Our results lead us to ask the following questions: (1) Are the neo-sex chromosomes of $B$. noroestensis in the initial state of the differentiation process? (2) If so, is a recent origin for B. noroestensis neo-sex chromosomes thus suggested? Probably we should suggest such a situation, based on melanopline neo-sex chromosome data, where in few cases the XR arm and neo-Y still seem to conserve their homology. Besides this, the conserved homology which allows for more than one chiasma at metaphase I suggests a recent evolutionary origin of neo-sex chromosomes. Even so, how could we explain the FN reduction? Moreover, we could not explain the observed chromosome number of the species using only a single chromosome rearrangement event. We propose rather that the atypical meiotic features 
of neo-sex chromosomes of $B$. noroestensis imply a complex origin through several chromosomal rearrangements. In melanoplines there is a single case where neo-XY chromosomes are the result of multiple chromosome rearrangements and where $\mathrm{Rb}$ fusions are not involved (e.g. D. vittatus) (Bidau \& Martí, 2001).

In light of these factors, we propose two models which may explain the origin of $B$. noroestensis neo-sex chromosomes. Firstly, a tandem fusion between two autosome pairs from the L group of the standard karyotype took place and became completely established, producing an unusually large telocentric autosome $\left(\mathrm{L}_{\mathrm{K}}\right)$ (Fig. $\left.4 \mathrm{a}\right)$. In the next step, a centric fusion between $\mathrm{L}_{\mathrm{K}}$ and the $\mathrm{X}$ chromosome produced a large submetacentric neo-X; the homologue of the fused autosome became the neo-Y (Fig. 4c). The second model involves a $\mathrm{Rb}$ fusion between two autosome pairs from the L group that became fixed, thereby producing a metacentric pair; in the next step a pericentric inversion involving the new metacentric pair occurred, producing a large telocentric autosome $\mathrm{L}_{\mathrm{D}}$ (Fig. 4b). Lastly, a centric fusion between $\mathrm{L}_{\mathrm{D}}$ and the $\mathrm{X}$ chromosome produced a submetacentric neo-X; again, the homologue of the fused autosome became the actual neo-Y (Fig. 4c).

It is possible that the first model could be the better explanation, being the most parsimonious hypothesis because it involves less chromosome rearrangements in the evolution of neo-sex chromosomes. Additionally, it is difficult to imagine this chromosome arrangement becoming established in large populations. Based on cytogenetic records in Orthoptera, it is possible to propose an explanation of what probably occurred during their origin (White et al., 1967; John \& Weissman, 1977). Even under the most favourable conditions, i.e. regularity in terms of synapsis and chiasma formation, tandem fusion heterozygotes will produce $50 \%$ of aneuploid gametes carrying both a deficiency or duplication. If this situation is compared with that of Robertsonian neo-XY heterozygotes, which produce a high number of euploids gametes, as occurs in normal male gametogenesis, selection is more drastic in the former case (White et al., 1967; White, 1973). It is possible that tandem fusion achieved initial success in small isolated populations (John \& Weissman, 1977); if this is so, the low vagility of the species could have accelerated the process, thereby increasing the frequency of such chromosome forms in a few generations.

Either way, current cytogenetic evidence in the genus cannot assist in understanding the evolution of this chromosomal arrangement if the neo-XY sex chromosome system of $B$. noroestensis occurred in a remote ancestor or if different chromosome rearrangements were incorporated independently in Boliviacris species. Hence, neo-sex chromosomes could provide a certain degree of adaptive advantage to the carrier organism, or sex; in any case, it could be an important mechanism by which increase of the frequency of this karyotypic variant within natural populations versus the previous arrangement might occur without detriment of the ongoing micro-evolutionary forces (such as genetic drift in small populations), pertaining at least at the beginning of the evolutionary history of neo-sex chromosomes (White, 1978; Rieseberg, 2001).

We can also make some final assessment concerning how probable these models are and implications of this neo-sex system in the context of Melanoplinae sex chromosome evolution. In South American Melanoplinae, there are three records of FN variation, especially including reductions. This feature could be explained only by multiple centric fusions events and also pericentric inversions, as were earlier proposed for Dichroplus silveiraguidoi Liebermann and D. pratensis Bruner (Orthoptera: Acrididae: Melanoplinae) (Cardoso et al., 1974; Sáez \& Pérez-Mosquera, 1977; Mesa et al., 1982). Besides, Mesa et al. (1982) described a $2 \mathrm{n}=19 / 20(\mathrm{M} / \mathrm{F})$ species (determined as Chlorus sp.) with all telocentric chromosomes and an $\mathrm{X} 0 / \mathrm{XX}$ sex chromosome determination mechanism. Moreover, White et al. (1967) reported the only case known which involves tandem fusion in the neo-sex chromosome origin. Within Dichroplus, there is one record of multiple rearrangements, including a sex chromosome-autosome tandem fusion $(D$. vittatus) (Bidau \& Martí, 2001) which supports their probable occurrence in the presently analyzed species.

Boliviacris noroestensis neo-sex chromosomes are an example of a recently established sex mechanism, mainly because the observed homology between a large distalinterstitial region of the XR and the neo-Y. Despite this cytogenetic feature which allows interstitial chiasmata, the low frequency of this karyotype within natural populations indicates regular meiotic behaviour of the system. Interstitial-distal chiasmata, as observed, would facilitate a convergent orientation and a normal segregation of the sex bivalent, whilst the neo-Y proximal-interstitial region (positively heteropycnotic) which was evidenced at early meiosis, points to an interruption in the degeneration process where previous rearrangement took place.

We conclude that $B$. noroestensis neo-sex chromosomes have recently arisen through a complex mechanism and, as such, represent the first example within the Melanoplinae. However, it is well known that chromosomal rearrangements like tandem fusions need time to reach fixation within populations and all the cytogenetic consequences that structural changes (very large asymmetry) cause to their carriers. We can also infer, from cytogenetic data in related species, that several rearrangements could be involved in the chromosome number variation and $\mathrm{FN}$ reduction in the studied species.

Finally, as shown in earlier taxonomic work by Ronderos \& Cigliano (1990), B. noroestensis is related to several Melanopline species originally assigned to the genus Dichroplus. From molecular and morphological data, Colombo et al. (2005) tested the monophyly of Dichroplus, and besides so doing, showed the evolutionary relationships between this group and related genera of Dichroplini. They also proposed an explanation to the karyotype diversification, suggesting that $\mathrm{X}$-autosomal centric fusions took place several times during the evolution of this group (Colombo et al., 2005). From the optimization of chromosomal characters on the topology derived from the combined morpho- 
logical and molecular analyses, centric fusions appeared in several independent branches among the phylogenetic trees thus produced. The evidence of multiple chromosome rearrangements $(\mathrm{A}-\mathrm{A} / \mathrm{X}-\mathrm{A})$ involved in the origin of typical karyotype as well as neo-sex chromosome systems in $D$. vittatus, $R$. bergi and D. silveiraguidoi largely support our models, as described above.

ACKNOWLEDGMENTS. The authors are grateful to the continuing support of the Consejo Nacional de Investigaciones Científicas y Técnicas (CONICET) and CEDIT (Comité Ejecutivo de Desarrollo e Innovación Tecnológica-Misiones) for the provision of postgraduate scholarships (AT and ERDC are both $\mathrm{PhD}$ candidates at the Universidad Nacional de Córdoba, Argentina). They also acknowledge the kind help of M.M. Cigliano for performing the taxonomic identification of the grasshopper specimens here used. ERDC is grateful to C.J. Bidau, D. Baldo and V. Calonga Solis for constructive criticism of the manuscript, whilst authors thank H. Loxdale for his helpful editorial comments.

\section{REFERENCES}

BACHTROG D. 2013: Y-chromosome evolution: emerging insights into processes of Y-chromosome degeneration. - Nature 14: 113-124.

BIDAu C.J. 1990: The complex Robertsonian system of Dichroplus pratensis (Melanoplinae, Acrididae). II Effects of the fusion polymorphisms on chiasma frequency and distribution. Heredity 64: 145-159.

BidAu C.J. \& MARTí D.A. 1995: Male and female meiosis in Robertsonian heterozygotes of Dichroplus pratensis (Acrididae). In: Brandham P.E. \& Bennett M.D. (eds): Kew Chromosome Conference IV. Royal Botanic Gardens, Kew, pp. 381-396.

Bidau C.J. \& Martí D.A. 2001: Meiosis and the Neo-XY system of Dichroplus vittatus (Melanoplinae, Acrididae): a comparison between sexes. - Genetica 110: 185-194.

Bidau C.J., Martí D.A. \& Castillo E.R.D. 2011: Inexorable spread: inexorable death? The fate of neo-XY chromosomes of grasshoppers. - J. Genet. 90: 397-400.

Bressa M.J., Papeschi A.G., VítKová M., KubíčKová S., Fuková I., Pigozzi M.I. \& Marec F. 2009: Sex chromosome evolution in cotton stainers of the genus Dysdercus (Heteroptera: Pyrrhocoridae). - Cytogenet. Genome Res. 125: 292-305.

CARbonell C.S \& Mesa A. 2006: Ronderosia ommexechoides: a new species of Brazilian Dichroplini (Orthoptera: Acrididae, Melanoplinae). - Neotrop. Entomol. 35: 632-637.

Cardoso H. \& Dutra A. 1979: The Neo-X Neo-Y sex pair in Acrididae, its structure and association. - Chromosoma 70: 323-336.

Cardoso H., Sáez F.A. \& Brum-Zorrilla N. 1974: Location, structure and behavior of $\mathrm{C}$-heterochromatin during meiosis in Dichroplus silveiraguidoi (Acrididae - Orthoptera). - Chromosoma 48: 51-64.

Castillo E.R.D., Bidau C.J. \& Martí D.A. 2010a: Neo-sex chromosome diversity in Neotropical melanoplinae grasshoppers (Melanoplinae, Acrididae). — Genetica 138: 775-786.

Castillo E.R.D., Bidau C.J. \& Martí D. A. 2010b: Sex- and neosex chromosomes in Orthoptera: a review. $-J$. Orthopt. Res. 19: $213-231$.

Castillo E.R.D., Taffarel A. \& Martí D.A. 2011: An alternative technique for mitotic grasshopper karyotyping: Fluorescent and C-banding in Adimantus ornatissimus (Orthoptera: Acrididae). - Rev. Cienc. Tecnol. 16: 31-35.
Charlesworth B. 2002: The evolution of chromosomal sex determination. In Short R. (ed.): The Genetics and Biology of Sex Determination. John Wiley, Chichester, pp. 207-219.

Charlesworth D., Charlesworth B. \& Marais G. 2005: Steps in the evolution of heteromorphic sex chromosomes. - Heredity 95: 118-128.

Colombo P., Cigliano M.M., Sequeira A.S., Lange C.E., Vilardi J.C. \& Confalonieri V.A. 2005: Phylogenetic relationships in Dichroplus Stål (Orthoptera: Acrididae: Melanoplinae) inferred from molecular and morphological data: testing karyotype diversification. - Cladistics 21: 375-389.

DíAz M. \& SÁEZ F. 1968: DNA Synthesis in the Neo-X Neo-Y sex determination system of Dichroplus bergi (Orthoptera: Acrididae). - Chromosoma 24: 10-16.

HewitT G.H. 1979: Orthoptera. Grasshoppers and crickets. In John B. (ed.): Animal Cytogenetics, Vol. 3. Insecta 1. Gebrüder Borntraeger, Berlin, pp. 1-170.

JACOBS D.H. 2004: The evolution of a neo-XY1Y2 sex chromosome system by autosome - sex chromosome fusion in Dundocoris nodulicarinus Jacobs (Heteroptera: Aradidae: Carventinae). - Chromosome Res. 12: 175-191.

JoHN B. 1983: The role of chromosome change in the evolution of orthopteroid insects. In Sharma A.K. \& Sharma A.N. (eds): Chromosomes in the Evolution of Eukaryotes. CRC Press, Boca Raton, pp. 1-110.

John B. \& Weissman D.B. 1977: Cytogenetic components of reproductive isolation in Trimerotropis thalassica and T. occidentalis. - Chromosoma 60: 187-203.

Kaiser V.B. \& Bachtrog D. 2010: Evolution of sex chromosomes in insects. - Annu. Rev. Genet. 44: 91-112.

Martí D.A. \& BidAu C.J. 1995: Male and female meiosis in a natural population of Dichroplus pratensis (Acrididae) polymorphic for Robertsonian translocations: A study of chiasma frequency and distribution. - Hereditas 123: 227-235.

Martí D.A. \& Bidau C.J. 2001: Synapsis in Robertsonian heterozygotes and homozygotes of Dichroplus pratensis (Melanoplinae, Acrididae) and its relationship with chiasma patterns. - Hereditas 134: 245-254.

Mesa A. 1961: Morfología fálica y cariología de Neuquenina fictor (Rehn) (Orthoptera - Acridoidea). - Comun. Zool. Mus. Hist. Nat. Montevideo 5: 1-11.

Mesa A. 1962a: Cariología de Dichroplus bergi Stål (Orthoptera: Acrididae). - Revta Agricult. Piracicaba 37: 41-47.

Mesa A. 1962b: Los cromosomas de Eurotettix lilloanus Lieb (Orthoptera, Catantopidae). — Acta Zool. Lilloana 18: 99-104.

Mesa A. \& Mesa R.S. 1967: Complex sex determining mechanisms in three species of South American grasshoppers (Orthoptera, Acridoides). - Chromosoma 21: 163-180.

Mesa A., Ferreira A. \& Carbonell C.S. 1982: Cariología de los acridoideos neotropicales: estado actual de su conocimiento y nuevas contribuciones. - Ann. Soc. Entomol. Fr. 18: 507-526.

Mesa A., Fontanetti C.S. \& Garcia-Novo P. 2001: Does an Xautosome centric fusion in Acridoidea condemn the species to extinction? - J. Orthopt. Res. 10: 141-146.

Palacios-Gimenez O.M., Castillo E.R., Martí D.A. \& CabralDE-Mello D.C. 2013: Tracking the evolution of sex chromosome systems in Melanoplinae grasshoppers through chromosomal mapping of repetitive DNA sequences. - BMC Evol. Biol. 13: 167.

Pannell J.R. \& Pujol B. 2009: The paradoxical spread of a new Y chromosome: a novel explanation. — Trends Ecol. Evol. 24: 59-63.

RIESEBERG L.H. 2001: Chromosomal rearrangements and speciation. - Trends Ecol. Evol. 17: 351-358. 
Ronderos R.A. \& Cigliano M.M. 1990: Notas para una revisión del género Dichroplus Stål. 1. Boliviacris, nuevo género de Dichropli (Orthoptera, Acrididae, Melanoplinae). — Bol. Soc. Biol. Concepción Chile 61: 135-144.

Rufas J. 1985: Contribución de las técnicas de impregnación argéntica al estudio de los cromosomas de Ortópteros. - Orthoptera 1: 227-255.

SÁEz F.A. 1963: Gradient of heterochromatinization in the evolution of the sexual system "neo-X neo-Y". - Portug. Acta Biol. (A) 7: 111-138.

SÁez F.A. \& Pérez-Mosquera G. 1977: Structure, behaviour and evolution of the chromosomes of D. silveiraguidoi (Orthoptera, Acrididae). - Genetica 47: 105-114.

Sahara K., Yoshido A. \& Traut W. 2012: Sex chromosome evolution in moths and butterflies. — Chromosome Res. 20: 83-94.

Sumner A.T. 1972: A simple technique for demonstrating centromeric heterochromatin. — Exp. Cell Res. 75: 304-306.

Traut W. 1999: The evolution of sex chromosomes in insects: Differentiation of sex chromosomes in flies and moths. - Eur. J. Entomol. 96: 227-235.
Traut W. \& Marec F. 1997: Sex chromosome differentiation in some species of Lepidoptera (Insecta). - Chromosome Res. 5: 283-291.

Traut W., Sahara K. \& Marec F. 2007: Sex chromosomes and sex determination in Lepidoptera. - Sex. Dev. 1: 332-346.

Vitturi R., Colomba M., Volpe N., Lannino A. \& Zunino M. 2003: Evidence for male X0 sex-chromosome system in Pentodon bidens punctatum (Coleoptera: Scarabaeoidea: Scarabaeidae) with X-linked 18S-28S rDNA clusters. - Genes Genet. Syst. 28: 427-432.

White M.J.D. 1973: Animal Cytology and Evolution. Cambridge University Press, Cambridge, 496 pp.

White M.J.D. 1978: Modes of Speciation. W.H. Freeman, San Francisco, 455 pp.

White M.J.D., Blackith R.E., Blackith R.M. \& Cheney J. 1967 : Cytogenetics of the viatica group of Morabine grasshoppers. The "coastal" species. - Aust. J. Zool. 15: 263-302.

Received September 3, 2013; revised and accepted February 25, 2014 Prepublished online May 6, 2014 